\title{
Image processing of alos palsar satellite data, small unmanned aerial vehicle (UAV), and field measurement of land deformation
}

\author{
Husnul Kausarian ${ }^{a, 1, *}$, Josaphat Tetuko Sri Sumantyo b,2, Dewandra Bagus Eka Putra ${ }^{a, 3}$, \\ Adi Suryadi a, ${ }^{a,}$, Gevisioner ${ }^{c, 5}$ \\ ${ }^{a}$ Geological Engineering Department, Faculty of Engineering, Universitas Islam Riau, Pekanbaru, Indonesia \\ ${ }^{b}$ Center for Environmental Remote Sensing, Advance Integration Science, Chiba University, Chiba, Japan \\ c Research and Development Board, Government of Riau Province, Pekanbaru, Indonesia \\ ${ }^{1}$ husnulkausarian@eng.uir.ac.id; ${ }^{2}$ jtetukoss@faculty.chiba-u.jp; ${ }^{3}$ dewandra.bagus@eng.uir.ac.id; ${ }^{4}$ adisuryadi@eng.uir.ac.id \\ ${ }^{5}$ irgevisioner@gmail.com \\ * corresponding author
}

ARTICLE INFO

\section{Article history}

Received June 8, 2018

Revised July 4, 2018

Accepted July 17, 2018

Keywords

Pekanbaru

Siak bridges

Small unmanned aerial vehicle (UAV)

Differential interferometric synthetic

Aperture radar (DInSAR)

Deflection

\section{ABSTRACT}

Pekanbaru, Indonesia is connected by four big bridges, Siak Bridge; I, II, III and IV. The quality of the Siak bridges deteriorated seriously at this time. Geological mapping for the land subsidence potency was conducted using small Unmanned Aerial Vehicle (UAV) in the Siak Bridge areas. The study of the Siak bridges are supported by the Differential Interferometric Synthetic Aperture Radar (DInSAR) analysis using ALOS PALSAR satellite data, and the deflection observation that occurs in Siak III Bridge was observed by field measurement. The results of $3 \mathrm{D}$ model analysis showed that there is no negative land deformation. DInSAR analysis shows the amount of positive deformation of Siak I is $81 \mathrm{~cm}$, Siak II is $48 \mathrm{~cm}$, Siak III is $89 \mathrm{~cm}$, and Siak IV is 92 . Deflection on Siak III Bridge was detected at around $25-26 \mathrm{~cm}$. These models could be used as a new way of measuring the bridge deformation on a big scale.

This is an open access article under the CC-BY-SA license.

\section{Introduction}

Pekanbaru (Fig. 1) is the capital city of Riau province, Indonesia, located at $101^{\circ} 14^{\prime}-101^{\circ} 34^{\prime} \mathrm{E}$ and $0^{\circ} 25^{\prime}-0^{\circ} 45^{\prime} \mathrm{N}$ at $5-50$ meters above sea level which Riau province is the central province in Sumatra Island with the outer part of this province is the one of Indonesia outer part known as Rupat Island [1]. Pekanbaru City has a strategic location in the centre of Sumatra Island. Due to this position, Pekanbaru City connects the north-south littoral of Sumatra, and it also connects the East and West of this island.

This importance of Pekanbaru City means it inevitably requires supporting infrastructures. One of these is bridges. Pekanbaru City was split into two main areas because the great river named the Siak River passes through its centre. The river is recognized as the deepest river in Indonesia. The Siak River divides Pekanbaru City into the Senapelan sub-district, the Rumbai sub-district and the Rumbai Pesisir sub-district.

The establishment of the bridge was a way of joining the various communities in Pekanbaru, and provides enormous positive impact by making Pekanbaru ground transportation much easier, but the construction of this bridge also posed a risk to the change of land-use and the condition of the bridge, due to the pressure exerted by the bridge itself and the traffic on it. The bridges are located on the Siak 
River area on Pekanbaru with the total number of Siak bridges are 4. These four bridges are situated in close proximity to one another. Siak I Bridge and Siak III Bridge are particularly close neighbours. They have some problems with regard to the requirement of a supporting infrastructure, when ready to be used, especially the Siak III Bridge. After 3 years of use, Siak III Bridge was closed in December 2013 because a high deflection occurred.

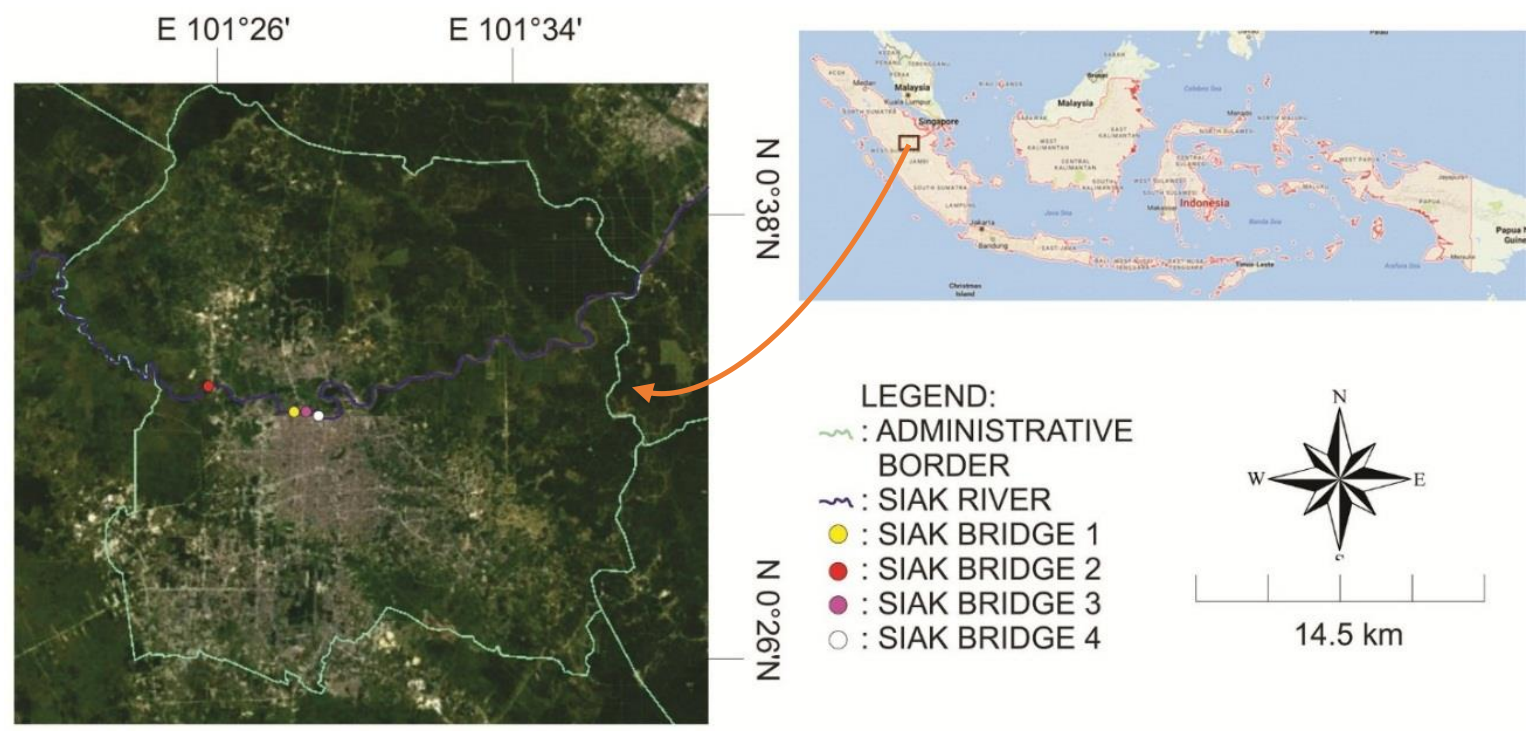

Fig. 1. Map of Pekanbaru City, Riau Province, Indonesia

Unmanned Aerial Vehicles (UASs) have become an interest for a variety of jobs and entertainment in the past 10 years especially for current technology limits UAS use to an assistive tool for the inspector to perform a bridge inspection faster, safer, and without traffic closure [2]. İn case of using the Synthetic Aperture Radar (SAR) data, the deflection of the bridge has been monitored [3]. Over years the application of SAR satellite data has been widely performed, ranging from monitoring ground deformation in small and big areas to monitoring single infrastructures, such as building, dam, and bridge [4] - [7]. The Previous works show that the measurement of bridge deflection has been conducted and completely discussed to find the solving. However, it was not developed a complete data usage by integrating processing UAV data, satellite data, and measurement data in the field. Therefore, this research aims to maximize results which are obtained for deflection measurements that occur on bridges, and to determine the effect the construction of the bridge had on the land.

\section{Method}

Three methodologies were used for this research. Field mapping on Siak I, Siak II, Siak III and Siak IV Bridges took place using a small Unmanned Aerial Vehicle (UAV) or known as drone [8], [9] with these specifications: a built-in camera with FOV (Field Of View) $94^{\circ} 20 \mathrm{~mm}$ ( $35 \mathrm{~mm}$ format equivalent) f/2.8 lens, $1 / 2.3$ " sensor and effective pixels: $12 \mathrm{M}$ connected to the built-in GPS. Pictures were taken over 2 weeks for all the bridges, starting from 20 November 2017 until 3 December 2017. The pictures were processed to produce 3D models of the mapping area [10] - [14].

Land-site deformation measurement [15] - [17] of the bridge stand was measured using differential interferometry [18] - [21] measurement with ALOS PALSAR level 1.1 data [22], [23]. The date of ALOS PALSAR data taken for these areas are from 25 May 2007 to 20 April 2011, which matches with the span of time during which Siak III Bridge was built for the first time.

The data is analysed to choose the baseline (B) by firstly looking at the highest number. This baseline is influenced by topography. The influence of topography (h) in interferograms is given by:

$$
\phi_{\text {topo }}=-\frac{4 \pi \cdot B^{+}}{\lambda \cdot R_{1} \cdot \sin \theta_{0}}
$$


where $\phi$ is phase, $\lambda$ is wavelength, $R_{1}$ is radiant of the wave and $\theta_{0}$ is incidence angle. After selecting the data, the co-registration process will generate (Fig. 2) an accurate determination of phase differences.

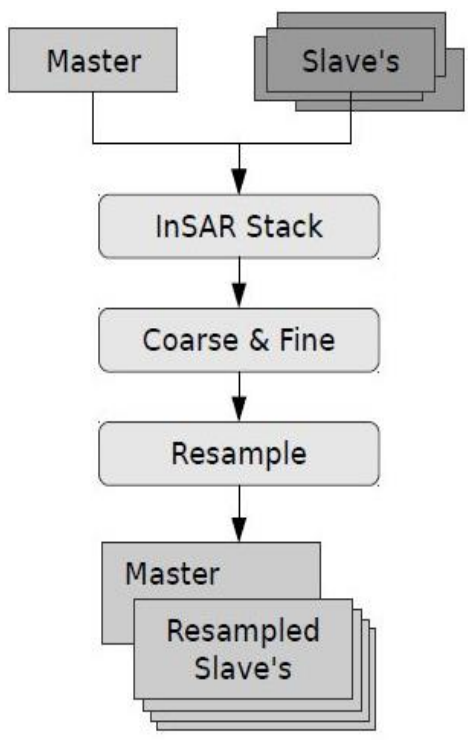

Fig. 2. Co-registration process

Co-registration produces the will be-combined master and slave data. Co-registration data is ready for interferogram generation with flattened conditions and the result comes from calculating complex correlation coefficient between two acquisitions or coherence for generating the topographic phase correction. By reducing the interferogram phase and the topographic phase correction, the differential interferogram will be generated.

$$
\text { Differential }_{\text {Interferogram }}=\text { phase }_{\text {ifg }}-\text { phase }_{\text {topo }}
$$

Generating the topographic phase correction will be able to produce the phase filtering. We used 2 types of Goldstein filtering with $0.5 \times 0.5$ and $0.3 \times 0.3$ coherence threshold. The data is ready to be unwrapped after finishing the phase filtering process. The compilation of wrapped phase and unwrapped phase data will produce a vertical displacement map which is given by the following calculation:

$$
\text { vertical }_{\text {displacement }}=\frac{\phi \_ \text {unwrapped. } \lambda}{-4 \pi \cdot \cos \theta_{i}}
$$

Where $\phi$ is phase, $\lambda$ is wavelength and $\Theta_{i}$ is refraction angle.

The vertical displacement map will generate the vertical displacement map reference, as the reference to combine with pixel from the point we chose by substituting equation 2 with the following equation:

$$
\text { vertical }_{\text {displacement_reference }}=\left(\text { vertical }_{\text {displacement }}+\text { pixel }_{\text {value }}\right)
$$

The calculation of the low coherence masking area combined with the vertical displacement reference for getting, the result of interferometry. The calculation of the masking area is given by:

$$
\text { ver }_{\text {disp_ref_mask }}=I F(\text { Coherence value }) \geq(\text { Scale value in meter }) \text { THEN } 1 \text { ELSE NaN }
$$

Geocoding and projection map that used the WGS84 with SRTM [24] 3sec digital elevation model and the nearest neighbor resampling method in the Range-Doppler terrain correction resulted in the masking of the vertical displacement reference file.

Furthermore, to get the exact body bridge deflection [25] - [27], field observation [28], [29] and measurement [30] - [33] were used to analyze the deflection of the Siak III Bridge. 


\section{Results and Discussion}

\subsection{Area Monitoring Using Small Unmanned Aerial Vehicle (UAV)}

A small UAV (Fig.3) was used for mapping. To get the pictures of the study area, rendering software was used. The 3D model shows the land area of the bridge sites for Siak I, Siak II, Siak III and Siak IV Bridges and the residential area. The result shows no significant changes on the land especially with regard to land subsidence and land deformation. This analysis is also supported by the ALOS PALSAR differential interferometry analysis data.
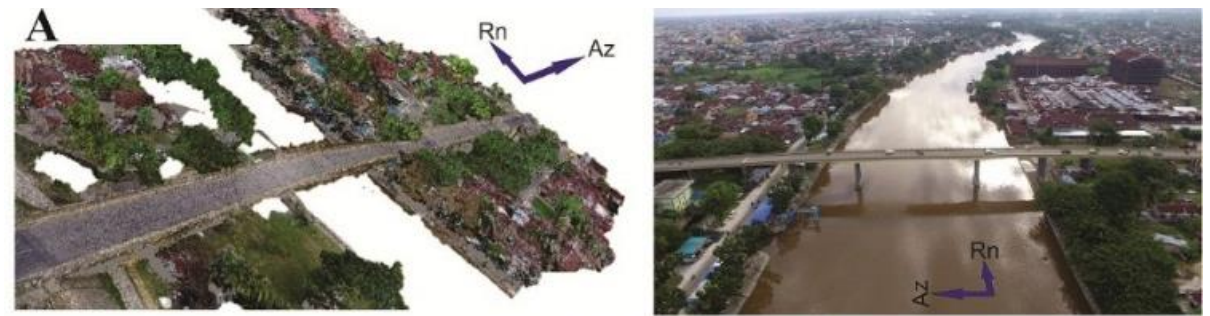

B
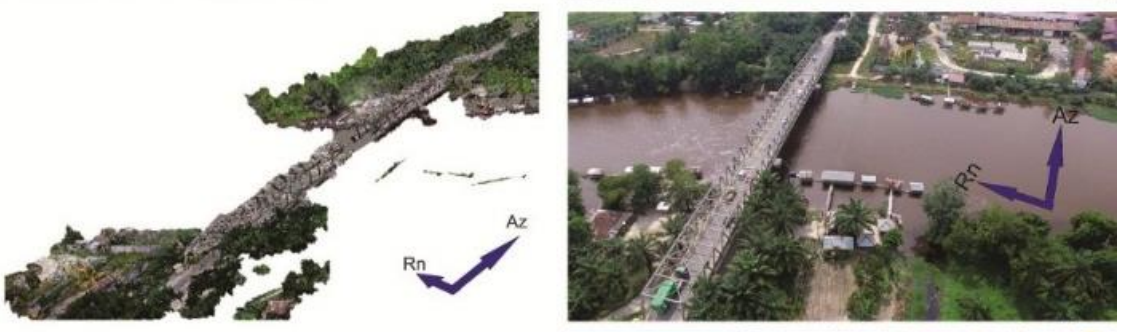

C
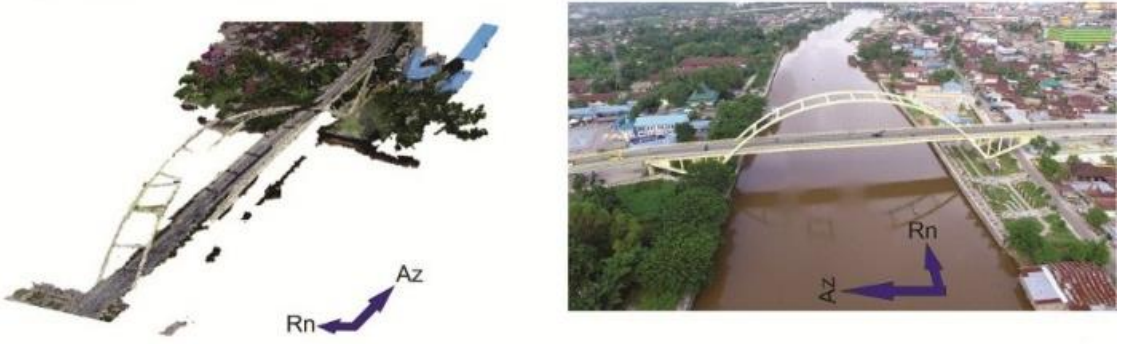

D
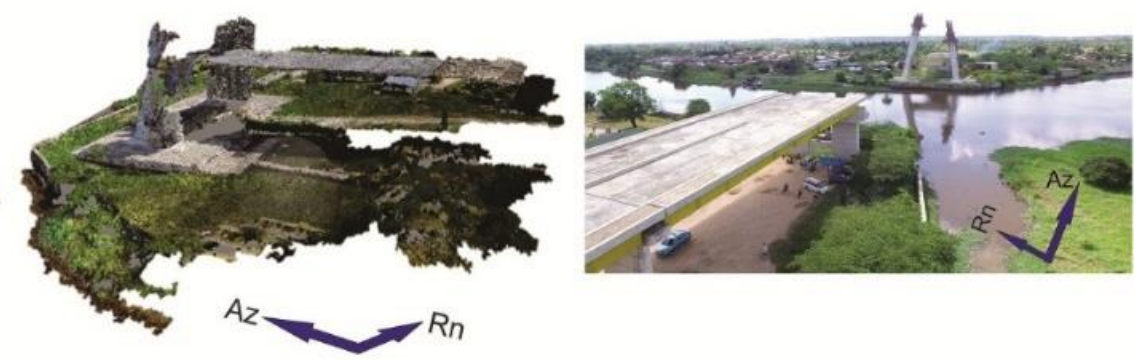

Fig. 3. Location of Siak bridges taken by a small UAV (A: Siak I Bridge, B: Siak II Bridge, C: Siak III Bridge, D: Siak IV Bridge)

\subsection{Differential interferometry Synthetic Aperture Radar (DInSAR) Analysis}

Land deformation mapping on the site of Siak I, Siak II, Siak III, Siak IV Bridges shows the number that impacted on Pekanbaru and around the Siak bridges, based on data analysis of ALOS PALSAR in the time range of Siak III Bridge construction on 25 May 2007 and 20 April 2011. ALOS PALSAR Data Processing for these scenes produces a differential interferogram (Fig. 4) which was used for further processing to obtain the amount of land deformation in this study area.

Based on Differential Interferometric Synthetic Aperture Radar (DInSAR) analysis (Fig. 5), Pekanbaru City has the lowest deformation value of $-540.36 \mathrm{~mm}$ in several southern and western areas. The highest deformation value is $1,274.50 \mathrm{~mm}$ in the eastern part of Pekanbaru City. Differential Interferometric Synthetic Aperture Radar (DInSAR) analysis was used with 2 types of scale which are 0.01 and 0.1. Differential Interferometric Synthetic Aperture Radar (DInSAR) analysis also shows no 
land subsidence in Pekanbaru in the range of 2007-2011 on the scale that shows the deformation changes. This analysis also shows the topography information of Pekanbaru City which in the east area has higher topography than the south and west areas.
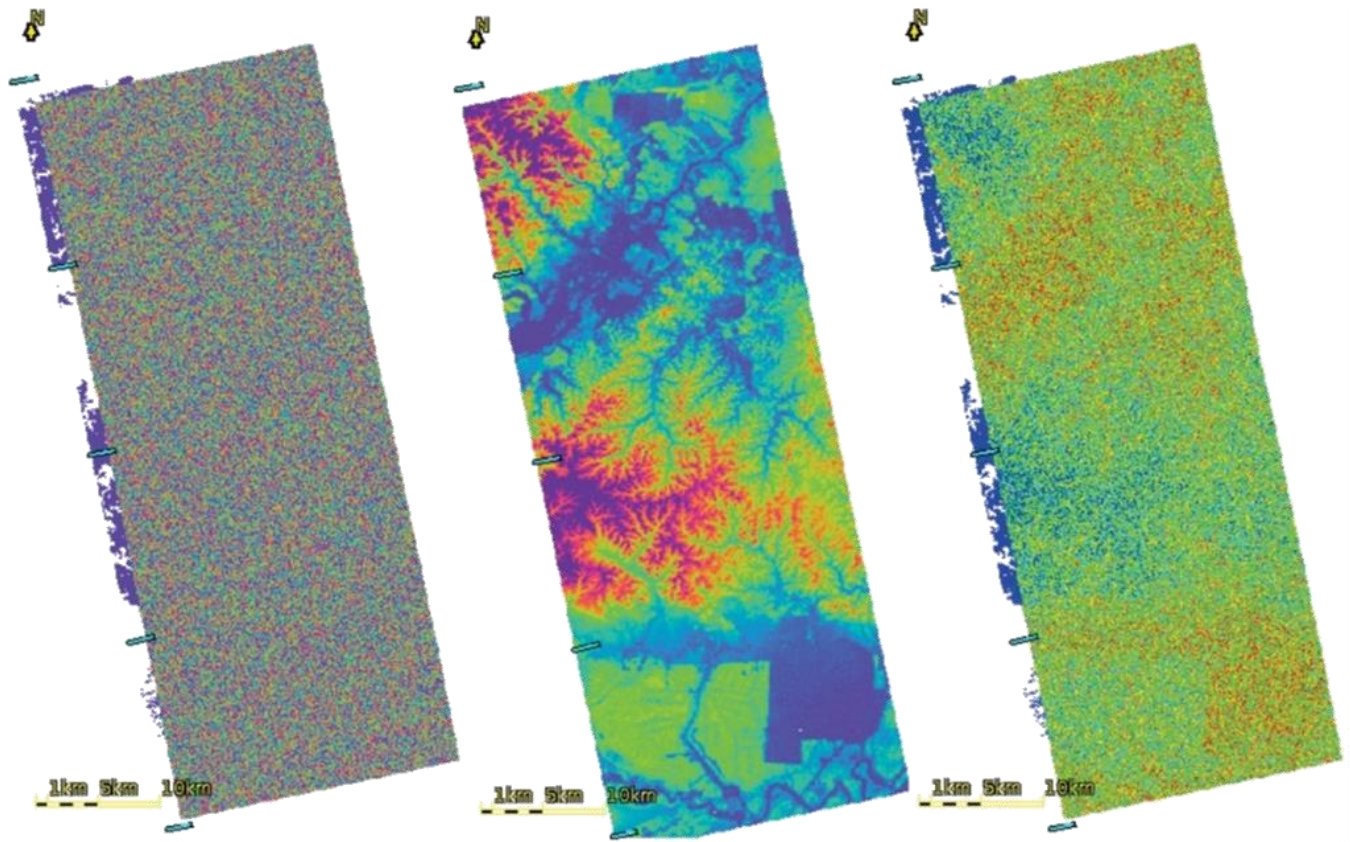

Fig. 4. Differential Interferogram of Pekanbaru City (right), resulting from phase interferogram (left) minus phase topography (middle)
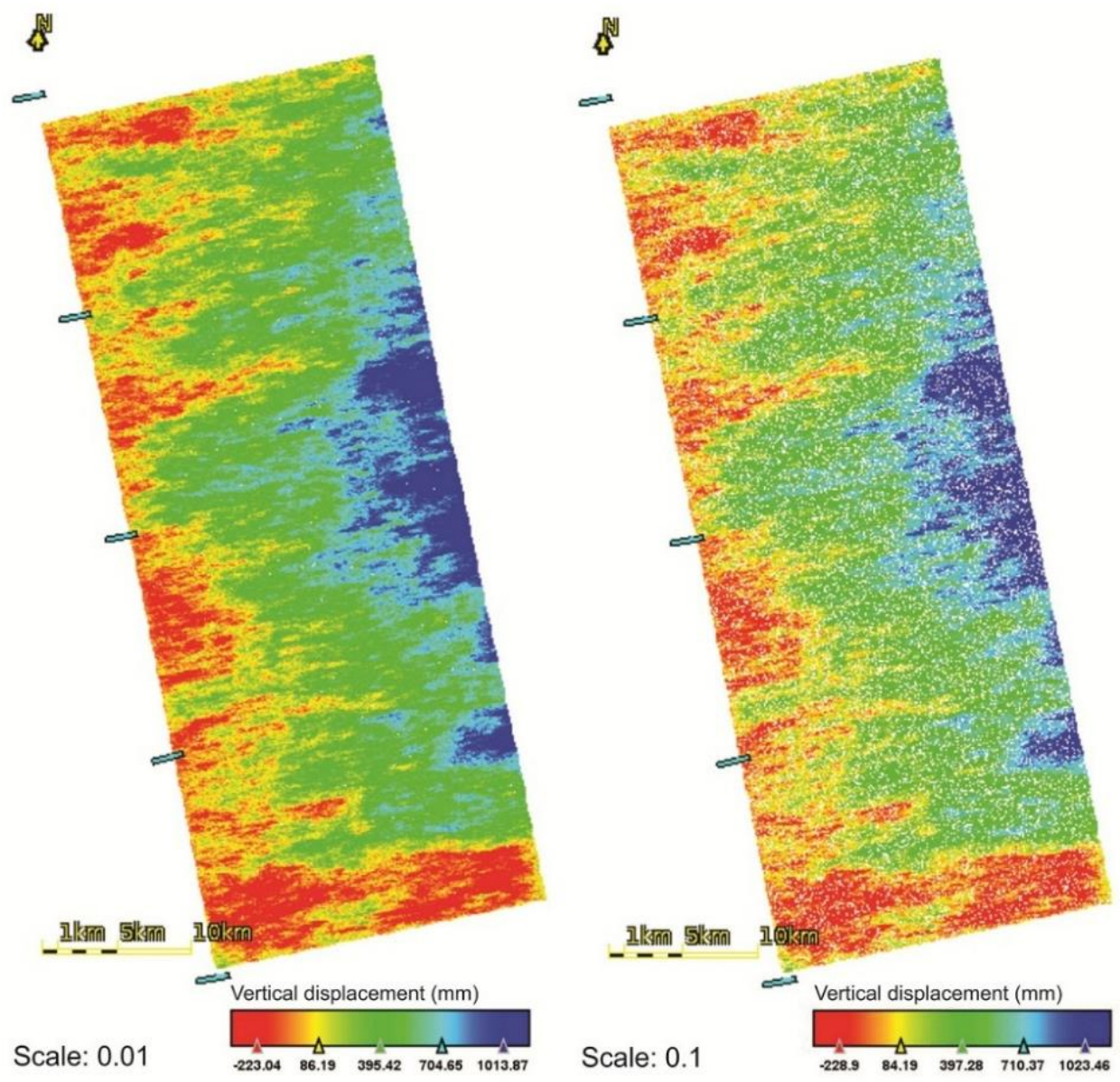

Fig. 5. Differential interferometry image for Pekanbaru City 
Differential interferometry analysis on the whole of the Siak Bridges site (Fig. 6) shows the deformation in these areas are positive. Siak I Bridge has $81 \mathrm{~cm}$ deformation value. Siak II Bridge has 48 $\mathrm{cm}$ deformation value and this site has the lowest value compared to any other site of the Siak Bridges. For Siak III Bridge, the deformation value is $89 \mathrm{~cm}$, and for Siak IV Bridge, the deformation value is 92 $\mathrm{cm}$. Differential Interferometric Synthetic Aperture Radar (DInSAR) analysis for Siak I Bridge, Siak II Bridge, Siak III Bridge and Siak IV Bridge did not detect any significant negative land deformation. This result means that the entire site of the Siak Bridges did not impact on the failed bridge's deflection.

$101^{\circ} 26^{\prime} E$

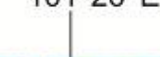

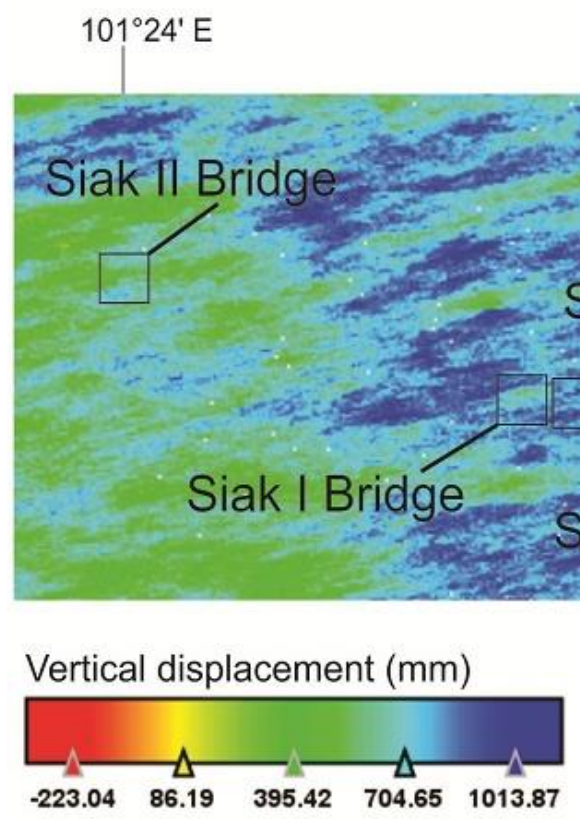

$\cos$

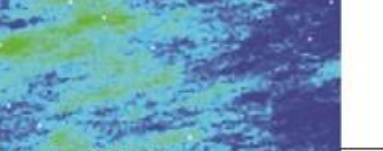

Siak $11 \mathrm{Bridge}-\frac{\mathrm{z}}{\mathrm{z}}$

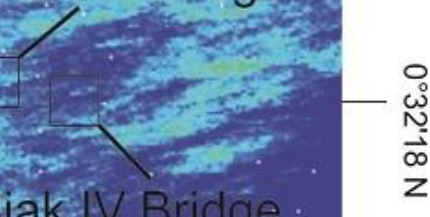

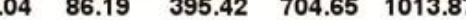

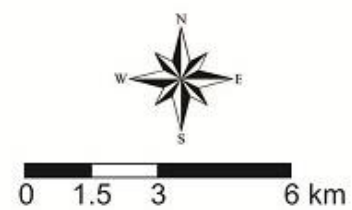

Fig. 6. Differential interferometry on the site of Siak I Bridge, Siak II Bridge, Siak III Bridge and Siak IV Bridge

The different value of land deformation between the site of Siak III Bridge and the other Siak bridges did not reveal any significant difference, especially when compared to the Siak I Bridge, which is to the right of Siak III Bridge. DInSAR analysis shows Siak I Bridge has a reduced amount, greater than Siak III Bridge. The big difference in decline exhibited by Siak I Bridge is $7 \mathrm{~cm}$. Siak I Bridge should have a greater potential for failure since the Siak I Bridge is older than the Siak III Bridge. However, Siak III Bridge showed a high decrease, especially in the body with the deflection at the centre of the bridge. Here, the cause of the bridge failure are could be a design error or an inappropriate construction. It still require further investigation to find the actual causal factors to explain such failure.

\subsection{Bridge Deflection Value from Field Measurement}

The deflection measurement of Siak III Bridge (Fig. 7) found that the camber is negative. It curve and bend down as much as $25-26 \mathrm{~cm}$ (Fig. 8). This downward curve would certainly affect its durability. It proves that an error occurred in the design/construction, where there is a shift towards a horizontal arc, resulting in stretching, but Siak III Bridge was forced to be constructed in the opposite direction and it caused a curvature in the bridge's floor. Supposedly, this bridge's strength was reported for able to withstand loads of up to 80 tons. This was different from the design of this bridge which had to be able to withstand loads of up to 300 tons.

Siak III Bridge was bolstered by its arc steel profile. This means the center point load of this bridge depends on the strength of this arc steel profile. The arc steel profile must be designed very well, to hold the floor load of this bridge. The deflection on the center floor of this bridge leads to the conclusion that the arc steel profile is not good enough to hold the load given by the load floor of Siak III Bridge. 

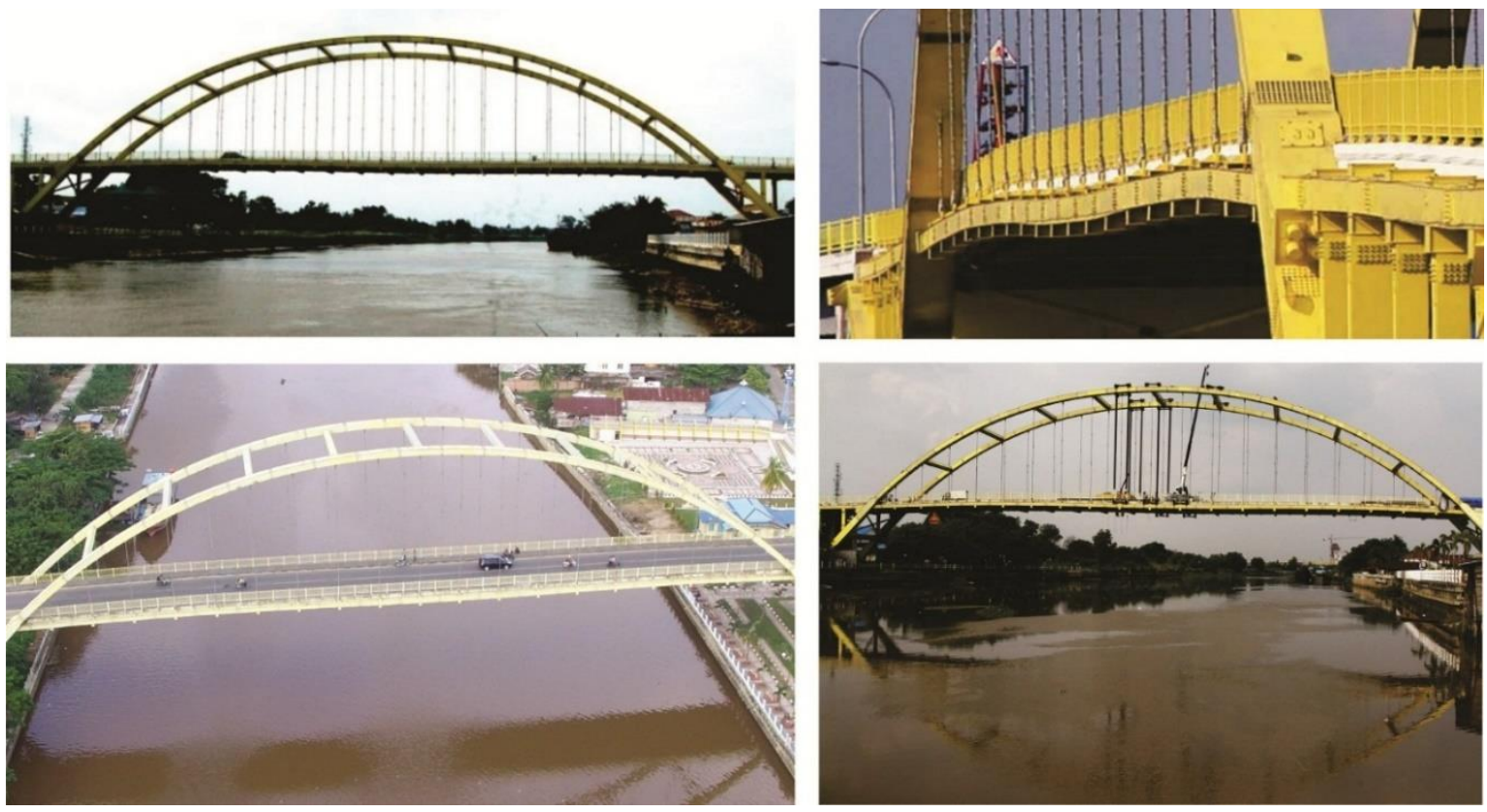

Fig. 7. Clockwise: Siak III bridge after being built completely; the deflection while used; repairing process; after repairing
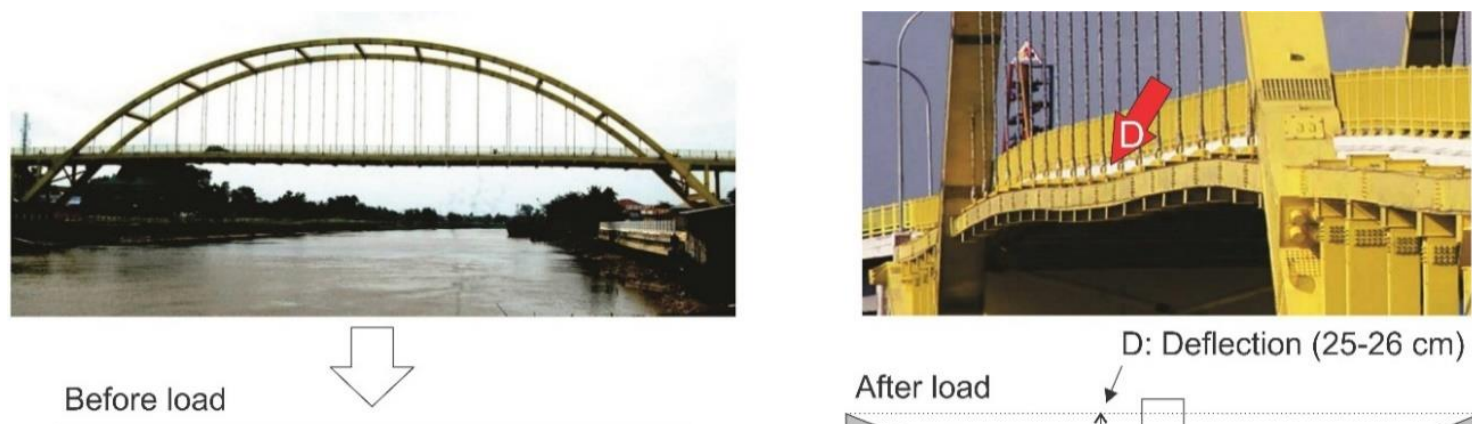

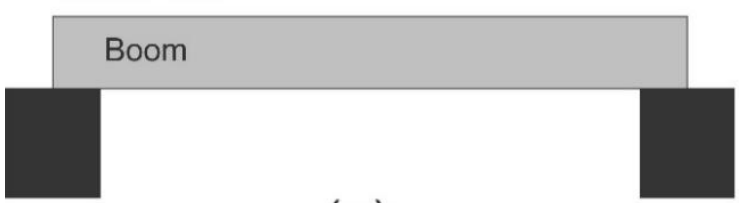

(a)
D: Deflection $(25-26 \mathrm{~cm})$

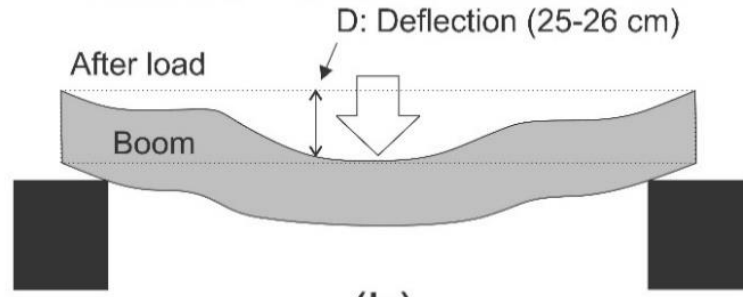

(b)

Fig. 8. The illustration of the Siak III bridge deflection after built completely and used for one year after, (a) Siak III bridge after built completely, (b) The deflection after three years used

Based on these measurements, there was a suggestion that the mistake happened in the process of this bridge's design/construction which led to the negative chamber and a decrease in arch structure which resulted in the very high frequency in the four hangers of this bridge. This was considered as an indication that there was high stress on the hanger, caused by the deflection which means even more strain on the hanger. An excessive extension means that there was a big force contribution to the occurred high stress on the hanger.

The amount of deflection is $25-26 \mathrm{~cm}$, and permanently, the stress on the hanger is estimated as over the limit of melting elastic. As with any other steel structures, the melting condition is the strength limit of the steel structure. This means the structural safety of the bridge was also judged to reach its limit. Another possible reason for the deflection in Siak III Bridge is that the error in the construction process that resulted in a pre-chamber that did not match the original plan. This error indicated the varied decline that occurred after the bridge was weighed down. As a result, this reduction causes a different stress on both the deflected hanger part and the non-deflected hanger part. The different stress obviously causes diverse frequency on the hanger. 


\section{Conclusion}

The result of the study on the Siak bridges in Pekanbaru is expected to provide input for city government in preparing for the construction and preservation of the existing bridges. For Siak III Bridge especially, which experienced deflection in the middle of the bridge, repairs are needed immediately in order to avoid a more fatal failure. Meanwhile, research information is also expected to be used as information on the Siak IV Bridge's construction process. The result of the mapping using a small UAVs shows no area with decreased significantly in all regions around the site of the Siak bridges. UAV mapping results, supported by the analysis of land deformation DInSAR analysis for ALOS PALSAR Data in Pekanbaru. The finding certifies that the absence of negative surround Siak I Bridge, Siak II Bridge, Siak III Bridge and Siak IV Bridge sites. Another supporting analysis is based on a direct observation of the Siak bridges. From the direct observation, a big deflection was found on Siak III Bridge and not on the Siak I Bridge and Siak II Bridge.

\section{Acknowledgment}

This work was supported by Research Board of Universitas Islam Riau and the EORC JAXA for providing ALOS PALSAR data; Japanese Government National Budget. The authors would like to thank Josaphat Microwave Remote Sensing Laboratory (JMRSL) at CEReS, Chiba University who also provides the ALOS PALSAR data.

\section{References}

[1] H. Kausarian, J.T.S. Sumantyo, H. Kuze, D. Karya, and S. Wiyono, "The origin and distribution of silica mineral on the recent surface sediment area, Northern Coastline of Rupat Island, Indonesia." ARPN Journal of Engineering and Applied Sciences, Vol. 12(4), pp. 980-989, 2016, available at: http://www.arpnjournals.org/ jeas/research_papers/rp_2017/jeas_0217_5714.pdf .

[2] S. Dorafshan and M. Maguire, "Bridge inspection: human performance, unmanned aerial systems and automation," Journal of Civil Structural Health Monitoring, Vol. 8(3), pp. 1-34, 2018, doi: https://doi.org/ 10.1007/s13349-018-0285-4.

[3] L. Zhang, L, Q. Sun, and J. Hu, "Potential of TCPInSAR in Monitoring Linear Infrastructure with a Small Dataset of SAR Images: Application of the Donghai Bridge, China," Applied Sciences, Vol. 8(3), pp. 425439, 2018, doi: https://doi.org/10.3390/app8030425.

[4] G. Grenerczy and U. Wegmüller, "Persistent scatterer interferometry analysis of the embankment failure of a red mud reservoir using ENVISAT ASAR data," Natural Hazards, Vol. 59, pp. 1047-1053, 2011, doi: https://doi.org/10.1007/s11069-011-9816-6.

[5] J.J. Sousa, I. Hlavácová, M. Bako nn, M. Lazecký, G. Patricio, P. Guimaraes, A.K. Ruiz, L. Bastos, A. Sousa, and R. Bento, "Potential of multi-temporal InSAR techniques for bridges and dams monitoring," Procedia Technology, Vol. 16, pp. 834-841, 2014, doi: https://doi.org/10.1016/j.protcy.2014.10.033.

[6] G. Fornaro, D. Reale, and S. Verde, "Bridge thermal dilation monitoring with millimeter sensitivity via multidimensional SAR imaging," IEEE Geoscience Remote Sensing Letter, Vol. 10, pp. 677-681, 2013, doi: https://doi.org/10.1109/LGRS.2012.2218214.

[7] M. Crosetto, O. Monserrat, M. Cuevas-González, N. Devanthéry, G. Luzi, and B. Crippa, "Measuring thermal expansion using X-band persistent scatterer interferometry," ISPRS Journal of Photogrammetry Remote Sensing, Vol. 100, pp. 84-91, 2015, doi: https://doi.org/10.1016/j.isprsjprs.2014.05.006.

[8] B. Shi and C. Liu, "UAV for landslide mapping and deformation analysis," in International Conference on Intelligent Earth Observing and Applications. Guilin: International Society for Optics and Photonics 2015, p. 98080P, 2015, doi: https://doi.org/10.1117/12.2207411.

[9] Y. Liu, Y. Deng, and C.S. Cai, "Deflection monitoring and assessment for a suspension bridge using a connected pipe system: a case study in China," Structural Control and Health Monitoring, Vol. 22(12), pp. 1408-1425, 2015, doi: https://doi.org/10.1002/stc.1751.

[10] T. Fernández, J.L. Pérez, J. Cardenal, J.M. Gómez, C. Colomo, and J. Delgado, “Analysis of landslide evolution affecting olive groves using uav and photogrammetric techniques," Remote Sensing, Vol. 8(10), pp. 837-866, 2016, doi: https://doi.org/10.3390/rs8100837. 
[11] J. Xu, P. Ye, Q. Li, H. Du, Y. Liu, and D. Doermann, "Blind image quality assessment based on high order statistics aggregation," IEEE Transactions on Image Processing, Vol. 25(9), pp. 4444-4457, 2016, doi: https://doi.org/10.1109/TIP.2016.2585880.

[12] C. Kerdvibulvech, "A methodology for hand and finger motion analysis using adaptive probabilistic models," EURASIP Journal on Embedded Systems, Vol. 18(1), pp. 1-9, 2014, doi: https://doi.org/ 10.1186/s13639-014-0018-7.

[13] M.Z. Lubis, S. Pujiyati, D.S. Pamungkas, M. Tauhid, W. Anurogo, and H. Kausarian, "Coral reefs recruitment in stone substrate on Gosong Pramuka, Seribu Islands, Indonesia," Biodiversitas, Vol. 19(4), pp. 1451-1458, 2018, doi: https://doi.org/10.13057/biodiv/d190435.

[14] F. Cigna, V.J. Banks, A.W. Donald, S. Donohue, C. Graham, D. Hughes, J.M. McKinley, and K. Parker, "Mapping Ground Instability in Areas of Geotechnical Infrastructure Using Satellite InSAR and Small UAV Surveying: A Case Study in Northern Ireland," Geosciences, Vol. 7(3), pp. 51-75, 2017, doi: https://doi.org/ 10.3390/geosciences7030051.

[15] C.S. Hsieh, T.Y. Shih, J.C. Hu, H. Tung, M.H. Huang, and J. Angelier, "Using differential SAR interferometry to map land subsidence: a case study in the Pingtung Plain of SW Taiwan," Natural Hazards, Vol. 58(3), pp. 1311-1332, 2011, doi: https://doi.org/10.1007/s11069-011-9734-7.

[16] H. Kausarian, Batara, D.Bagus.E. Putra, A. Suryadi, and M.Z. Lubis, "Geological Mapping and Assessment for Measurement of Electric Grid Transmission Lines as the Supporting of National Energy Program in West Sumatera Area, Indonesia,"International Journal on Advanced Science, Engineering and Information Technology, Vol. 8(3), pp. 856-862, 2018, doi: http://dx.doi.org/10.18517/ijaseit.8.3.4069.

[17] E. Chaussard, S. Wdowinski, E. Cabral-Cano, and F. Amelung, "Land subsidence in central Mexico detected by ALOS InSAR time-series," Remote Sensing of Environment, Vol. 140, pp. 94-106, 2014, doi: https://doi.org/10.1016/j.rse.2013.08.038.

[18] R. Lanari, F. Casu, M. Manzo, G. Zeni, P. Berardino, M. Manunta, and A. Pepe, "An overview of the small baseline subset algorithm: A DInSAR technique for surface deformation analysis," Pure and Applied Geophysics, Vol. 164(4), pp. 637-661, 2007, doi: https://doi.org/10.1007/s00024-007-0192-9.

[19] S. Hongyun, Y. Songlin, and L. Guang, "The application of InSAR in the deformation monitoring for road engineering-A case study: Dujiangyan, China," In Intelligent Computation Technology and Automation (ICICTA) 2011 International Conference 2, 2011, pp. 732-734, doi: https://doi.org/10.1109/ ICICTA.2011.469.

[20] J.T.S. Sumantyo, M. Shimada, P.P. Mathieu, and H.Z. Abidin, "Long-term consecutive DInSAR for volume change estimation of land deformation," IEEE Transactions on Geoscience and Remote Sensing, Vol. 50(1), pp. 259-270, 2012, doi: https://doi.org/10.1109/TGRS.2011.2160455.

[21] M.N. Jebur, B. Pradhan, and M.S. Tehrany, "Using ALOS PALSAR derived high-resolution DInSAR to detect slow-moving landslides in tropical forest: Cameron Highlands, Malaysia," Geomatics, Natural Hazards and Risk, Vol. 6(8), pp. 741-759, 2015, doi: https://doi.org/10.1080/19475705.2013.860407.

[22] H. Kausarian, J.T. Sri Sumantyo, H. Kuze, D. Karya, and G.F. Panggabean, "Silica Sand Identification using ALOS PALSAR Full Polarimetry on The Northern Coastline of Rupat Island, Indonesia," International Journal on Advanced Science, Engineering and Information Technology, Vol. 6(5), pp. 568-573, 2016, doi: https://doi.org/10.18517/ijaseit.6.5.920.

[23] H. Kausarian, J.T. Sri Sumantyo, H. Kuze, J. Aminuddin, and M.M. Waqar, "Analysis of Polarimetric Decomposition, Backscattering Coefficient, and Sample Properties for Identification and Layer Thickness Estimation of Silica Sand Distribution Using L-Band Synthetic Aperture Radar," Canadian Journal of Remote Sensing, Vol. 43(2), pp. 95-108, 2017, doi: https://doi.org/10.1080/07038992.2017.1286935.

[24] H. Kausarian, Batara, and D.B.E. Putra, "The Phenomena of Flood Caused by the Seawater Tidal and its Solution for the Rapid-growth City: A case study in Dumai City, Riau Province, Indonesia," Journal of Geoscience, Engineering, Environment, and Technology, Vol. 3(1), pp. 39-46, 2018, doi: https://doi.org/ 10.24273/jgeet.2018.3.01.1221.

[25] C. Gentile and A. Saisi, "Ambient vibration testing and condition assessment of the Paderno iron arch bridge (1889)," Construction and Building Materials, Vol. 25(9), pp. 3709-3720, 2011, doi: https://doi.org/10.1016/ j.conbuildmat.2011.04.019. 
[26] B. Pan, D. Wu, and Y. Xia, "An active imaging digital image correlation method for deformation measurement insensitive to ambient light," Optics \& Laser Technology, Vol. 44(1), pp. 204-209, 2012, doi: https://doi.org/10.1016/j.optlastec.2011.06.019.

[27] N. Lu, M. Beer, M. Noori, and Y. Liu, "Lifetime Deflections of Long-Span Bridges under Dynamic and Growing Traffic Loads," Journal of Bridge Engineering, Vol. 22(11), pp.04017086, 2017, doi: https://doi.org/10.1061/(ASCE)BE.1943-5592.0001125.

[28] Y.C. Sung, T.K. Lin, Y.T. Chiu, K.C. Chang, K.L. Chen, and C.C. Chang, "A bridge safety monitoring system for prestressed composite box-girder bridges with corrugated steel webs based on in-situ loading experiments and a long-term monitoring database," Engineering Structures, Vol. 126, pp. 571-585, 2016, doi: https://doi.org/10.1016/j.engstruct.2016.08.006.

[29] C. Lü, W. Liu, Y. Zhang, and H. Zhao, "Experimental estimating deflection of a simple beam bridge model using grating eddy current sensors," Sensors, Vol. 12(8), pp. 9987-10000, 2012, doi: https://doi.org/10.3390/ s120809987.

[30] J.H. Yi, S. Cho, and C.B. Yun, "Two-Step Indirect Static Deflection Estimation of Bridges Based on Ambient Acceleration Measurements," Experimental Techniques, Vol. 37(3), pp. 33-45, 2013, doi: https://doi.org/ 10.1111/j.1747-1567.2011.00737.x.

[31] M.Z. Lubis, W. Anurogo, A. Hanafi, H. Kausarian, H. M. Taki, and S. Antoni, "Distribution of benthic habitat using Landsat-7 Imagery in shallow waters of Sekupang, Batam Island, Indonesia," Biodiversitas, Vol. 19(3), pp. 1117-1122, 2018, doi: https://doi.org/10.13057/biodiv/d190346.

[32] H. Kausarian, "Rock Mass, Geotechnical and Rock Type Identification Using SASW and MASW Methods at Kajang Rock Quarry, Semenyih, Selangor Darul Ehsan," Journal of Ocean, Mechanical and Aerospace Science and Engineering, Vol. 26, pp. 7-12, 2015, available at: http://isomase.org/JOMAse/ Vol.26\%20Dec\%202015/26-2.pdf.

[33] L. Tian and B. Pan, "Remote bridge deflection measurement using an advanced video deflectometer and actively illuminated LED targets," Sensors, Vol. 16(9), pp. 1-13, 2016, doi: https://oi.org/10.3390/ s16091344. 